\title{
Problematika Anak Pekerja Migran di Tulungagung dalam Perspektif Bimbingan dan Konseling
}

(Problems of Child Migrant Workers in Tulungagung in Guidance and Counseling Perspective)

\author{
Wikan Galuh Widyarto ${ }^{1 *}$, Machsun Rifauddin ${ }^{2}$ \\ ${ }^{1}$ Program Studi Bimbingan Konseling Islam, Fakultas Ushuluddin Adab dan Dakwah, Institut Agama Islam Negeri \\ Tulungagung, Jalan Mayor Sujadi Timur No. 46, Tulungagung, Jawa Timur, 66221, Indonesia \\ ${ }^{2}$ Program Studi Ilmu Perpustakaan dan Informasi Islam, Fakultas Ushuluddin Adab dan Dakwah, Institut Agama Islam \\ Negeri Tulungagung, Jalan Mayor Sujadi Timur No. 46, Tulungagung, Jawa Timur, 66221, Indonesia \\ *corresponding author, e-mail: wikan@iain-tulungagung.ac.id
}

Article received: February $26^{\text {th }} 2020$; revised: May $9^{\text {th }} 2019$; accepted: May $14^{\text {th }} 2019$

\begin{abstract}
Migrant workers are foreign exchange earners but also cause social problems, especially for children who are left behind. This study aimed to explain the problems experienced by children of migrant workers guidance and counseling point of view. A qualitative approach with a case study design was deployed in this study. Four children of migrant workers were recruited as the key informants in this study, while the supporting informants were their grandparents and mothers/fathers who take care of them at home. Data were collected using interview and List of Community Issues (LOCI). Data analysis was performed by reducing, presenting, and verifying data, as well as drawing conclusions. The validity of the data was tested using data triangulation. Findings suggest that the problems faced by children of migrant workers are health, economic, family, religion and moral problems, personal, social and organizational relationships, occupation, study habits and romance problems. These findings can be used as a basis for developing guidance and counseling programs to facilitate the growth and development of migrant workers' children.
\end{abstract}

Keywords: problematic behavior; migrant workers' children; guidance and counseling

\begin{abstract}
Abstrak: Pekerja migran adalah penghasil devisa, namun juga menimbulkan masalah sosial khususnya pada anak-anak yang ditinggalkan. Penelitian ini bertujuan untuk menjelaskan permasalahan yang dialami anak pekerja migran secara komprehensif dari sudut pandang bimbingan dan konseling. Penelitian ini menggunakan pendekatan kualitatif dengan desain studi kasus. Empat anak pekerja migran merupakan informan kunci dalam penelitian ini, sedangkan informan pendukungnya adalah kakeknenek, ibu/ayah yang mengasuh mereka di rumah. Data dikumpulkan dengan wawancara dan List of Community Issues (LOCI). Analisis data dilakukan dengan mereduksi, menyajikan, memverifikasi data, dan mengambil kesimpulan. Keabsahan data diuji triangulasi data. Temuan penelitian menunjukkan bahwa permasalahan yang dihadapi anak pekerja migran adalah masalah kesehatan, ekonomi, keluarga, agama dan moral, pribadi, hubungan sosial dan berorganisasi, jabatan, kebiasaan belajar serta permasalahan asmara. Temuan ini dapat digunakan sebagai dasar dalam menyusun program bimbingan dan konseling untuk memfasilitasi pertumbuhan dan perkembangan anak pekerja migran.
\end{abstract}

Kata kunci: perilaku problematik; anak pekerja migran; bimbingan dan konseling 


\section{PENDAHULUAN}

Orangtua memiliki tugas utama untuk mengasuh anak agar menjadi individu yang sehat secara fisik maupun mental, memiliki sikap tanggungjawab secara nyata, dan menjelma menjadi individu dewasa yang kreatif sehingga mampu mengembangkan pola hubungan yang bermakna dalam kehidupannya. Orangtua sebagai pengasuh anak, perlu untuk lebih peduli, menyayangi, menghargai, dan memberikan penguatan (reinforcement) kepada anak (Setiawati et al., 2017) karena perkembangan positif anak juga tergantung pada bagaimana orangtua mampu menciptakan lingkungan yang mendukung. Keadaan tersebut menjadi sangat krusial ketika dihadapkan pada kondisi orangtua yang menjadi pekerja migran. Dalam hal ini, orangtua pekerja migran tidak ada waktu membimbing anak, termasuk persoalan perawatan, pemeliharaan dan pengasuhan anak (Riasih, 2018).

Kondisi orangtua dan anak yang berjauhan berdampak pada pertumbuhan dan perkembangan anak. Sebagaimana ditemukan oleh Kholis, (2017) salah satu dampaknya adalah anak pekerja migran memiliki orientasi studi lanjutan yang rendah. Tidak sampai disitu, penelitian lain menyebutkan bahwa anak pekerja migran memilih untuk menjadi migran sebagaimana orangtuanya dan tidak memilih melanjutkan sekolah, mereka juga banyak menghabiskan waktu luang di lingkungan warung kopi, tidak taat kepada orangtua, meminta sesuatu dengan paksa, menolak makan, mengalami masalah kesehatan, anak juga tidak memiliki hak identitas, tidak melaksanakan aktivitas keagamaan (sholat dan mengaji), serta ditemukan kekerasan terhadap anak (Kholis, 2017; Purwatiningsih, 2016; Suryadi, 2017; Wahyuningsih \& Wulan, 2019).

Selaras dengan hal tersebut, temuan Chusna et al., (2017) memperlihatkan beberapa indikator yang menunjukkan rendahnya moralitas anak pekerja migran Indonesia, seperti: (1) pada aspek pengetahuan moral, indikator yang masuk dalam kategori rendah yaitu: kesadaran moral, penilaian nilai moral, dan pemikiran moral; (2) pada aspek perasaan moral indikator yang masuk dalam kategori rendah yaitu kendali diri; (3) pada aspek tindakan moral terdapat satu indikator yang rendah yaitu keinginan. Lebih jauh, sebuah penelitian menunjukkan bahwa $80 \%$ anak pekerja migran di Kabupaten Tulungagung memiliki masalah di lingkungan sekolah seperti: membolos ketika jam pembelajaran di kelas, merokok, minum minuman keras, berpakaian acak-acakan, merasa minder (tidak percaya diri), hiperaktif dan kurang menunjukkan sikap jujur (Pramono, 2018). Permasalahan anak pekerja migran sangatlah kompleks dan perlu mendapatkan penanganan dengan baik.

Salah satu peran bimbingan dan konseling adalah mengoptimalkan tumbuh-kembang anak. Layanan bimbingan dan konseling seharusnya dapat meningkatkan aspirasi karier, meningkatkan kesuksesan studi, mengembangkan kompetensi anak berdasarkan potensinya, pendidikan karakter, mengembangkan aspek pribadi, sosial, belajar dan karier, menyelesaikan pelbagai permasalahan, serta membantu menyesuaikan diri terhadap lingkungan sekolah (Basmalah, Endang, \& Lestari, 2016; Muslihati, 2019; Nugraha \& Rahman, 2017; Pangestuti, 2017; Ramadhani, 2017; Supriyanto, 2016; Widodo, 2009). Tentu hal tersebut akan mampu memberikan dampak pada anak pekerja migran seperti terselesaikannya masalah-masalah yang sedang dialami, tercapainya tugas-tugas perkembangan anak sesuai tahapannya, membantu memahami dan menerima dirinya sendiri, serta meningkatkan prestasi akademiknya.

Berdasarkan berbagai fenomena yang terjadi pada anak pekerja migran dan juga didukung hasil penelitian terdahulu, masalah anak pekerja migran Indonesia menarik untuk dikaji lebih mendalam. Pada penelitian sebelumnya, jenis permasalahan yang kerap terjadi pada anak pekerja migran dilihat pada sudut pandang pendidikan lanjutan, remitansi, moralitas, dan pola asuh. Penelitian ini berupaya untuk mengeksplorasi permasalahan anak pekerja migran secara komprehensif, kemudian meninjaunya dari sudut pandang bimbingan dan konseling. Oleh karenanya, penelitian ini bertujuan untuk mengetahui dan mendeskripsikan masalah yang dialami oleh anak pekerja migran, mengungkap faktor-faktor penyebab terjadinya permasalahan tersebut, dan mengembangkan solusi penyelesaian masalah melalui layanan bimbingan dan konseling.

\section{METODE}

Penelitian ini menggunakan pendekatan kualitatif dengan desain studi kasus untuk mengungkap gejala secara holistik-kontekstual melalui pengumpulan data, meninjau dan mengeskplorasi, serta mengambil keputusan dari peristiwa alami dengan memanfaatkan peneliti sebagai instrumen kunci. 
Pemilihan tersebut bertujuan untuk mendapatkan gambaran secara komprehensif mengenai permasalahan yang dialami anak pekerja migran melalui pengumpulan dan pengkajian data yang mendalam (Bogdan \& Biklen, 2007).

\section{Sumber Data}

Instrumen utama dalam penelitian kualitatif adalah kehadiran peneliti. Keterlibatan peneliti dimaksudkan untuk mendapatkan data yang akurat, serta mendalam dan mendapatkan jawaban sampai pada titik jenuh. Subjek penelitian utama adalah anak pekerja migran di Kabupaten Tulungagung. Lokasi penelitian yakni di Kecamatan Besuki, Desa Keboireng. Snowball sampling merupakan teknik yang digunakan peneliti, yang mana subjek penelitian pada awalnya berjumlah sedikit dan lama kelamaan menjadi besar karena keperluan penelitian. Snowball sampling merupakan istilah yang digunakan untuk prosedur pengambilan sampel yang memperbolehkan subjek penelitian menyediakan informasi tidak hanya tentang dirinya sendiri melainkan juga tentang subjek lainnya (Johnston et al., 2015).

Informasi diperoleh dari empat subjek penelitian. Kriteria dari subjek penelitian yakni: (1) anak pekerja migran yang diketahui dari wawancara awal dengan petugas desa; (2) anak pekerja migran yang dapat mengomunikasikan secara verbal atas interpretasinya tentang topik penelitian; dan (3) kemudahan akses terhadap anak pekerja migran terkait informasi sesuai topik penelitian. Dari keempat subjek penelitian, peneliti mendapatkan data yang telah mencapai taraf kejenuhan dan sesuai dengan tujuan penelitian. Secara lebih detail, deskripsi subjek disajikan pada tabel 1.

\section{Teknik Pengumpulan Data}

Data primer yang digunakan peneliti adalah data yang diperoleh melalui daftar cek masalah komunitas, dan wawancara mendalam (in-depth interview). Daftar cek masalah komunitas adalah daftar isian masalah yang telah disesuaikan dengan komunitas yang diteliti yaitu anak pekerja migran. Daftar cek masalah komunitas memiliki fungsi untuk memetakan permasalahan secara komprehensif dengan cara melakukan check list berdasarkan jawaban dari subjek penelitian. Wawancara mendalam (in-depth interview) merupakan serangkaian pertanyaan yang ditujukan kepada subjek penelitian dan pengasuh sesuai dengan fokus penelitian. Dengan wawancara mendalam (in-depth interview) peneliti mendapatkan data yang tepat dan akurat dari subjek penelitian.

\section{Teknik Analisis Data}

Analisis data digunakan untuk mengatur urutan data, mengorganisasikan, dan mengkategorikan temuan-temuan penelitian. Pada penelitian ini analisis data mengacu pada Bogdan \& Biklen, (2007) yang menggunakan: reduksi data, penyajian data (display data), verifikasi dan pengambilan keputusan. Pada proses reduksi data, peneliti melakukan pengodean (coding) dengan menerapkan prinsip dan kategorisasi sesuai tujuan dan fokus penelitian (Bogdan \& Biklen, 2007), format pengodean disajikan pada tabel 2 .

\section{Teknik Pengecekan Keabsahan Data}

Dalam penelitian ini, pengecekan keabsahan data dilakukan dengan teknik triangulasi data. Triangulasi data digunakan untuk melakukan pemeriksaan data dengan memanfaatkan sesuatu di luar data untuk keperluan pengecekan atau pembanding terhadap data tersebut (Moleong, 2005). Uji kredibilitas (credibility) dilaksanakan dengan cara peneliti melakukan validitas internal terhadap hasil temuan penelitian dengan mewawancarai wakil subjek. Pengecekan anggota dilakukan dengan cara mengecek ulang hasil List of Community Issues (LOCI), dan wawancara yang sudah peneliti catat dalam transkrip LOCI, serta transkrip wawancara. Uji dependabilitas (dependability) dilakukan dengan cara mengonsultasikan hasil LOCI, transkrip wawancara pada peneliti senior yakni Prof. Dr. Mujamil, M.Ag dan Dr. Ngainun Na'im, S.Ag., M.HI, hasil arahan dan masukan pada peneliti dijadikan sebagai validitas internal. Uji kepastian (confirmability) dilakukan dengan uji dependabilitas yakni mengaitkan proses yang telah dilakukan peneliti selama penelitian dan telah disepakati oleh subjek penelitian. Setelah melakukan uji kepastian, ditemukan bahwa hasil penelitian sudah sesuai dengan proses penelitian. 
Tabel 1. Deskripsi Subjek Penelitian

\begin{tabular}{|c|c|c|c|}
\hline $\begin{array}{c}\text { Inisial Subjek } \\
\text { Penelitian }\end{array}$ & $\begin{array}{c}\text { Orangtua } \\
\text { Pekerja migran }\end{array}$ & Pengasuh/ wali asuh & Keterangan \\
\hline KPE & Ayah dan ibu & Kakek dan nenek & $\begin{array}{l}\text { Usia } 10 \text { Tahun } \\
\text { Jenis kelamin perempuan } \\
\text { Agama Islam } \\
\text { Kondisi keluarga rukun dan harmonis }\end{array}$ \\
\hline YBE & Ayah & $\begin{array}{l}\text { Ibu kandung, kakek dan } \\
\text { nenek }\end{array}$ & $\begin{array}{l}\text { Usia } 9 \text { tahun } \\
\text { Jenis kelamin laki-laki } \\
\text { Agama Islam } \\
\text { Kondisi keluarga rukun dan harmonis }\end{array}$ \\
\hline AEL & Ibu & Kakek, nenek dan paman & $\begin{array}{l}\text { Usia } 14 \text { tahun } \\
\text { Jenis kelamin perempuan } \\
\text { Agama Islam } \\
\text { Kondisi keluarga bercerai }\end{array}$ \\
\hline $\mathrm{ADF}$ & Ibu & $\begin{array}{l}\text { Ayah, ibu tiri, kakek dan } \\
\text { nenek }\end{array}$ & $\begin{array}{l}\text { Usia } 15 \text { tahun } \\
\text { Jenis kelamin perempuan } \\
\text { Agama Islam } \\
\text { Kondisi keluarga bercerai }\end{array}$ \\
\hline
\end{tabular}

Tabel 2. Coding Penelitian

\begin{tabular}{clll}
\hline No. & Teknik Pengumpulan Data & \multicolumn{1}{c}{ Kode } & \multicolumn{1}{c}{ Keterangan } \\
\hline 1. $\begin{array}{l}\text { LOCI } \\
\text { (List of Community Issues) }\end{array}$ & $\begin{array}{l}\text { a. Data Utama DU/Li/Inisial Informan/JK/U/ } \\
\text { Tanggal-Bulan-Tahun }\end{array}$ & $\begin{array}{l}\text { a. DU: Data Utama } \\
\text { b. Li: LOCI (List of } \\
\text { Community Issues) }\end{array}$ \\
& & & c. JK: Jenis Kelamin \\
& & & d. U: Usia \\
2. Wawancara mendalam & a. Data Utama DU/Wn/Inisial Informan/ & a. DU: Data Utama \\
& (In-depth Interview) & JK/U/Tanggal-Bulan-Tahun & b. DT: Data Tambahan \\
& b. Data Tambahan DT/Wn/Inisial Informan// & c. Wn: Wawancara ke-... \\
& JK/U/Tanggal-Bulan-Tahun & d. JK: Jenis Kelamin \\
& & & e. U: Usia
\end{tabular}

\section{HASIL}

Banyak permasalahan yang dihadapi anak pekerja migran di Desa Keboireng, Besuki, Tulungagung. Permasalahan-permasalahan yang ditemukan dalam penelitian ini terkait dengan masalah kesehatan, ekonomi, keluarga, agama dan moral, pribadi, hubungan sosial dan organisasi, berhubungan dengan jabatan, kebiasaan pendidikan serta permasalahan asmara. Berikut beberapa kumpulan potongan transkrip wawancara yang terekam mengenai permasalahan yang dialami oleh anak pekerja migran:

Kalau masalah sakit itu ya sewajarnya mbak, kadang panas batuk flu, pernah opname tapi kata dokter itu cuma sakit biasa. Iya mbak, soalnya anaknya itu kan gemuk jadi sering keluar keringat. Iya mbak, setelah maghrib itu udah tidur. (DU/Wn/YBE/L/9 tahun/08-06-2019).

Nggeh nek ditinggal ibuk e niku jatahe susu pun wonten, niko pas tasek umur 1 tahun kan nggeh bapake tasek teng griyo, niku nggeh bapake sing numbasne susune sampek TK niku nggeh dereng pedot kaleh dot e niku, tapi bapake pun berangkat niki pun mboten ngedot maleh. Enggeh, enggeh kadang-kadang kulo bantu. Tapi nggeh sing katah ibuk e. (DT/Wn/KPE/P/10 tahun/12-06-2019).

Dari kecil sampai sekarang ya ikut nenek, kalau ada apa-apa ya sama nenek. Sejak kecil sampai dengan sekarang orangtuanya bercerai. Sejak umur 2,5 tahun ditinggal ibunya. Biasanya 2 tahun sekali pulang ibunya. (DU/Wn/AEL/P/14 tahun/16-06-2019).

Kalau masalah sholat sulit mbak, kadang maghrib itu mau kadang tidak, kalau di sekolah sudah pasti sholat dhuha dan dhuhur berjamaah di sekolahan. Di rumah sangat sulit, untuk masalah ngaji di sekolah ada dan kalau di rumah dia tidak mau karena katanya sudah ngaji di sekolah dan sudah lelah (DU/Wn/ YBE/L/9 tahun/08-06-2019) 
Iya mbak sering, wong yo YBE iku nakal banget mbak, mbendinten kulo kaleh utine niku cerewet. Kalau di rumah tidak mbak, dia kalau di rumah itu inginnya menang sendiri tapi kalau di sekolah dia pemalu dan menjadi kalahan. Larene niku nopo nggeh emosian tersinggung, nggeh sugetan. (DU/Wn/ YBE/L/9 tahun/08-06-2019).

Nggeh lek niku anu mas, gampang sugetan ngonten, gampang marah-marah, lak maem e nggak cocok mutung pilih tumbas maem dewe. Terus niku isinan lak enten tamu larene langsung nyelok kulo, mboten wani nerimo tamune. (DT/Wn/ADF/P/15 tahun/20-06-2019).

Alah wong cah males mbak, lak libur ya mek dilok tv neng omah. (DU/Wn/AEL/P/14 tahun/16-06-2019).

Endak mbak emboh AEL ki ndak tau cerito masalah ngono kui, tapi lak wong tuwek ya dukung ae mbak, manut bocah mengko lak dipekso malah bubrah. Wong tuwek mendukung mawon pilihan larenipun. (DU/Wn/AEL/P/14 tahun/16-06-2019).

Lak niku sekolah e budal e esuk wangsul e sore, kadang nggeh magrib, nggeh biasane kesel mboten tau belajar neng omah .(DT/Wn/ADF/P/15 tahun/20-06-2019).

Duko mas mboten sumerep niku, lak cowok dolan mriki dereng tahu. Lek enten kulo seneni. (DT/Wn/ $\mathrm{ADF} / \mathrm{P} / 15$ tahun/20-06-2019).

Ya mek kancane ngono kui mbak tapi ya bareng-bareng karo kancane wedok, cuek nek sama teman laki-laki (DU/Wn/AEL/P/14 tahun/16-06-2019).

Masalah kesehatan yang muncul pada anak pekerja migran di antaranya adalah: sakit flu, batuk, panas, dan pilek, namun tidak ada penyakit serius yang menjangkiti dan gizi anak terpenuhi dengan baik. Masalah keadaan kehidupan ekonomi yang dialami anak pekerja migran tidak ditemukan, karena anak dapat memenuhi semua keinginan dan kebutuhan dalam kehidupan sehari-hari, akan tetapi perlu adanya manajemen keuangan. Artinya tidak ada permasalahan terkait ekonomi, namun permasalahan terjadi pada tataran manajerial keuangan. Masalah keluarga juga menjadi permasalahan yang pelik, orangtua yang tidak harmonis dan berujung pada perceraian membuat anak tinggal dengan salah satu orangtuanya, namun ada juga subjek dengan orangtua yang hidup rukun dan harmonis, meski demikian karena terbentangnya jarak membuat anak merasa kurang mendapat kasih sayang.

Masalah agama dan moral yang dialami anak pekerja migran yakni belum bisa mempraktikan ibadah secara konsisten ketika berada di rumah, Berbeda ketika di sekolah, anak pekerja migran beribadah secara konsisten karena aturan yang diberlakukan. Sehubungan dengan masalah pribadi yang dialami anak pekerja migran, di antaranya adalah mudah malu, kurang percaya diri, merasa dirinya bos, mudah tersinggung, mudah emosi, kurang sabar, merasa ingin menang sendiri, memiliki sifat dingin dan memiliki sifat masa bodoh. Sedangkan untuk masalah hubungan sosial dan berorganisasi, anak cenderung takut mengenal orang lain, takut bergaul dengan orang yang lebih tua, bingung ketika berhadapan dengan khalayak umum, mudah tersinggung, sukar menerima kekalahan, selalu ingin berkuasa, mudah marah, mudah merasa malu, tidak sabaran, sukar menyesuaikan diri dengan orang lain.

Masalah hobi dan penggunaan waktu luang, anak lebih banyak menghabiskan waktunya untuk bersantai (menonton televisi, bermain gawai, bersantai di rumah). Masalah yang berhubungan dengan jabatan, anak merasa kebingungan untuk memahami ataupun memilih sekolah lanjutan yang akan dipilihnya. Adapun untuk masalah kebiasaan pendidikan, anak belum memiliki waktu belajar yang teratur, malas belajar, mudah mengantuk, dan merasa belajar adalah hal yang sulit dilakukan. Untuk permasalahan muda-mudi dan asmara, anak pekerja migran merasa sudah ada ketertarikan dengan lawan jenis, di samping itu anak juga merasa tidak tertarik untuk memikirkannya, merasa tabu/ tidak pantas/ jijik membicarakan soal cinta dan merasa cinta merupakan hal terlalu awal bagi anak.

Dapat diketahui bahwasanya pelbagai permasalahan yang dialami oleh anak pekerja migran disebabkan oleh pengasuhan yang dilakukan oleh orangtua pekerja migran dan belum optimalnya pengasuh (grandparenting) sebagai wali yang mendampingi tumbuh-kembang anak. Kunci kesuksesan mental anak bisa berkembang dengan baik ada pada orangtua, namun demikian orangtua pekerja migran tidak bisa serta merta memberikan pendampingan secara optimal karena keadaan. Berdasarkan hasil penelitian, orangtua pekerja migran mencerminkan pengasuhan yang lalai (neglectful parenting) dan gaya pengasuhan yang memanjakan (indulgent parenting), sehingga anak pekerja migran cenderung tidak memiliki kompetensi sosial yang baik, memiliki kontrol diri yang buruk dan tidak memiliki 
sikap independensi yang baik. Di samping itu, peran dukungan sosial yang diberikan pengasuh (grandparenting) cenderung memberikan gaya pengasuhan yang memanjakan (indulgent parenting). Hal tersebut terungkap dari hasil penelitian yang menunjukkan wali asuh cenderung membiarkan anak melakukan apa yang mereka inginkan. Pengasuh lebih memanjakan anak, sedikit memberikan tuntutan dan kontrol terhadap anak, sehingga anak tidak pernah belajar mengendalikan perilaku mereka sendiri dan selalu menuntut mendapatkan apa yang mereka inginkan.

\section{PEMBAHASAN}

\section{Permasalahan Anak Pekerja migran}

Permasalahan anak pekerja migran yang ditemukan dalam penelitian ini terkait dengan masalah kesehatan, ekonomi, keluarga, agama dan moral, pribadi, hubungan sosial dan berorganisasi, berhubungan dengan jabatan, kebiasaan pendidikan serta permasalahan asmara. Permasalahan tersebut terjadi dikarenakan faktor lingkungan keluarga yakni orangtua yang menjadi pekerja migran. Kontrol orangtua terhadap aktivitas keseharian anak pekerja migran kurang ketat sehingga menyebabkan terbentuknya beberapa masalah yang berpengaruh terhadap orientasi masa depan (karier) anak-anak pekerja migran (Kholis, 2017). Prinsipnya, orangtua memiliki tanggungjawab dalam pertumbuhan fisik dan perkembangan mental anak.

Dalam hal ini, orangtua pekerja migran tidak mampu memberikan pemenuhan tanggung jawab fisik dan mental secara optimal. Hal tersebut diperkuat sebuah hasil penelitian yang menyebutkan bahwa keterbatasan orangtua pekerja migran dalam memberikan pengasuhan jika tidak mendapatkan perhatian serius maka akan mengancam pertumbuhan dan perkembangan anak secara fisik, intelektual maupun sosialnya (Riasih, 2018). Menjadi pekerja migran merupakan sebuah solusi dalam hal permasalahan ekonomi yang akan berimplikasi pada investasi pendidikan bagi anak ( $\mathrm{Hu}, 2013$; Purwatiningsih, 2016; Romdiati, 2016). Anak-anak yang ditinggalkan orangtuanya menjadi pekerja migran banyak mengalami masalah psikososial seperti gangguan emosi, masalah perilaku maladaptif, hiperaktif, cenderung lebih pasif dalam mengatasi masalah yang muncul, baik masalah keluarga maupun dengan lingkungan pendidikannya (sekolah) dan proporsi terbesar stres anak juga tergolong dalam kategori tinggi (Puspitawati \& Setioningsih, 2011). Selaras dengan hal tersebut, kurangnya kehangatan dan kasih sayang yang tulus dari orangtuanya akan berdampak pada perkembangan anak di masa depan (Feist et al., 2018).

Anak pekerja migran perlu memenuhi kebutuhan psikologi dasar seperti menjalin hubungan secara kontinu dengan individu dewasa yang sangat mencintainya dan memiliki komitmen seumur hidup untuk mencurahkan perhatian, interaksi komunikasi yang stabil dan konsisten dalam memberikan lingkungan yang membuat anak dapat mengembangkan perilaku yang lebih beragam serta memperoleh pengetahuan yang lebih besar mengenai dunia (Brooks, 2012). Selaras dengan temuan penelitian ini, Fauziah et al., (2020) menjelaskan bahwasanya praktik pengasuhan dan keterlibatan orangtua memiliki peranan penting dalam meningkatkan konsep diri anak. Dalam hal pendidikan, keterlibatan orangtua, dan kerja sama orangtua akan berdampak pada kesiapan anak dalam bersekolah (Ip et al., 2016; Magdalena, 2013; Marti et al., 2018). Oleh karena itu, orangtua perlu mempertimbangkan dampak yang diakibatkan dari migrasi menjadi pekerja migran (Wahyuningsih \& Jatiningsih, 2017).

Peran dari pengasuh yakni kakek dan nenek (grandparenting) sebagai wali kerap kali kurang optimal. Anak yang diasuh oleh kakek dan nenek kerap menunjukkan perilaku yang bermasalah (maladaptif), gangguan emosional, dan tidak patuh pada pengasuh (Nurannisa et al., 2017; Wahyuningsih \& Wulan, 2016). Hal demikian merupakan akibat dari pengasuhan yang diberikan oleh kakek dan nenek yang memanjakan dan melayani (Fauziah et al., 2018). Oleh karenanya, penting untuk memahami model pengasuhan yang tepat untuk diterapkan pada anak pekerja migran bagi pengasuh. Selaras dengan hal tersebut Widiasari et al., (2017) menyebutkan bahwa pengasuh perlu memahami pentingnya model pengasuhan yang tepat sesuai dengan kebutuhan anak sehingga anak tidak kehilangan momen pentingnya di masa absorbment mind. Di samping itu, pengasuhan grandparenting hendaknya melakukan pembimbingan terhadap anak, memberikan nasihat, memberikan pujian untuk menambah semangat, melatih kemandirian anak dan memberikan hukuman apabila anak melanggar aturan yang 
berlaku (Eriyanti et al., 2019; Rahmawati \& Diana, 2016). Dapat diketahui bahwasanya pengasuhan pada anak pekerja migran, tidak hanya menjadi tanggung jawab dan dibebankan pada kakek dan nenek (grandparenting) melainkan orangtua pekerja migran tetap wajib bertanggungjawab.

Peran dari orangtua pekerja migran tidak hanya sebatas mengenai pemenuhan hak dasar anak seperti: makan, minum, pakaian, dan sejenisnya. Melainkan juga pemenuhan aspek psikologis secara optimal yang akan berdampak pada tumbuh kembang anak. Meskipun orangtua tidak bisa bertatap muka secara langsung karena menjadi pekerja migran, bukan berarti orangtua dapat lalai dalam memberikan pengasuhan dan cenderung memanjakan anak. Dengan lalai dan memanjakan anak, keinginan orangtua agar anak berhasil dalam hal akademik maupun kehidupan sosialnya adalah sebuah hal yang mustahil. Sikap lalai dalam pengasuhan dan memanjakan anak akan membuat kompetensi sosial anak rendah. Anak memiliki sikap yang tidak dewasa, kontrol diri yang rendah, kesulitan menghargai orang lain dan menunjukkan perilaku kenakalan remaja.

Pada sisi lain, pengasuh memiliki perananannya sendiri. Pengasuh (grandparenting) memiliki kontribusi besar terhadap tumbuh-kembang anak sebagai wali dari orangtua. Kontrol yang rendah dari pengasuh dan cenderung memanjakan hanya akan membuat anak pekerja migran menjadi raja kecil dalam kehidupannya. Dampaknya, anak menjadi lebih mendominasi, sulit diatur dan tidak patuh, egosentris serta memiliki kesulitan hubungan dengan teman sebaya. Oleh karenanya, kombinasi dan kolaborasi pengasuhan yang diberikan oleh orangtua pekerja migran dan pengasuh hendaknya mengedepankan sikap mendorong anak untuk menjadi mandiri, tetapi ada batasan dan kendali terhadap anak. Orangtua pekerja migran dan pengasuh melakukan pengasuhan yang demokratis yaitu tetap memberikan sikap hangat (warmly), dukungan psikologis, serta melatih anak berperilaku konstruktif. Dengan demikian, orangtua dapat mendorong anak perilaku dewasa, bertanggungjawab, mandiri dan bertindak sesuai dengan tugas perkembangannya.

\section{Faktor Penyebab Munculnya Problematika Anak Pekerja migran}

Beberapa faktor penyebab munculnya problematika anak pekerja migran yakni: pola pengasuhan orangtua pekerja migran yang mencerminkan pengasuhan yang lalai (neglecful parenting) dan gaya pengasuhan yang memanjakan (indulgent parenting), serta pengasuh (grandparenting) yang juga cenderung menerapkan gaya pengasuhan yang memanjakan (indulgent parenting). Dampak permasalahan anak pekerja migran yang ditemukan dalam penelitian ini terkait dengan masalah kesehatan, ekonomi, keluarga, agama dan moral, pribadi, hubungan sosial dan berorganisasi, berhubungan dengan jabatan, kebiasaan pendidikan serta permasalahan asmara.

Pada faktor kesehatan, anak pekerja migran tidak mengalami penyakit serius yang menjangkiti kesehatan. Pemenuhan gizi, kebugaran jasmani dan kesehatan mental akan berdampak pada tumbuh kembang anak, pemenuhan gizi yang dialami anak pekerja migran dapat membuat mereka terhindar dari stunting dan wasting serta memiliki korelasi positif dengan prestasi belajar (Putri, 2014; Sa'adah et al., 2014). Dalam permasalahan kesehatan, orangtua pekerja migran tidak bisa langsung memberikan pengawasan, sehingga mengandalkan pengasuh (grandparenting) yang dipercaya oleh orangtua. Guna memantau pertumbuhan anak pekerja migran, perlu komunikasi intensif. Meski demikian, pengasuh (grandparenting) mampu memberikan pemenuhan kesehatan terhadap anak pekerja migran sehingga terhindar dari stunting dan wasting.

Dari hasil penelitian, permasalahan ekonomi anak pekerja migran yang terjadi terkait pengelolaan uang, sedangkan pemenuhan ekonomi anak pekerja migran lebih dari cukup. Sebagaimana diutarakan oleh Kurniasari et al., (2019); Yuniastuti, (2014) hal tersebut terjadi karena perekonomian dapat tercukupi karena orangtua yang menjadi pekerja migran. Keluarga dengan kehidupan ekonomi yang tinggi tidak banyak mengalami kesulitan dalam memenuhi kebutuhan dasar anak, berbeda dengan orangtua dengan keadaan sosial ekonomi rendah (Langinan et al., 2014). Anak pekerja migran perlu belajar manajemen keuangan yang baik agar dapat membedakan antara kebutuhan dan keinginannya, sehingga uang saku dapat dimanfaatkan secara positif. Keterampilan manajemen keuangan tersebut hendaknya diberikan oleh orangtua pekerja migran dan pengasuh (grandparenting) dalam kehidupan sehari-harinya.

Masalah keluarga yang terjadi pada anak pekerja migran, terbagi menjadi empat kondisi yaitu: (1) anak tinggal dengan kakek dan neneknya karena kedua orangtuanya menjadi pekerja migran; (2) anak tinggal dengan ibu kandung bersama kakek dan neneknya karena ayah menjadi pekerja migran; (3) 
anak tinggal dengan kakek dan nenek dari ibu kandung dikarenakan kedua orangtua kandungnya telah bercerai (ayah kandung telah menikah lagi, sedangkan ibu kandung menjadi pekerja migran); (4) anak tinggal dengan ayah kandungnya, ibu tiri dan kakek serta nenek dari ayah kandungnya (ayah dan ibu kandungnya telah berpisah). Terkait pemenuhan hak anak oleh keluarga pekerja migran, meskipun terjadi kekosongan peran ibu yang bekerja sebagai pekerja migran, pemenuhan hak kasih sayang tetap dapat berjalan maksimal. Hal ini dikarenakan peran pengganti mampu menggantikan peran ibu secara baik, sedangkan pemenuhan hak pendidikan anak tidak cukup hanya diserahkan kepada lembaga pendidikan namun keluarga mempunyai peran penting dalam memberikan pendidikan bagi anak (Arfyansyah, 2016). Di samping itu, perubahan struktur keluarga, dikarenakan perceraian, penambahan anggota keluarga (menikah lagi), pengurangan keluarga (kematian), dan atau melakukan migrasi berpengaruh terhadap anak tumbuh-kembang anak (Berns, 2004). Kondisi yang dialami anak pekerja migran mengenai permasalahan keluarganya sangatlah rumit. Keadaan keluarga yang harmonis, keadaan keluarga yang bercerai, juga orangtua yang menjadi pekerja migran akan berdampak pada keadaan psikologis anak. Salah satu dampaknya adalah renggangnya hubungan antara orangtua dan anak, jika hal tersebut tidak segera mendapatkan solusi, anak pekerja migran dapat mengalami depresi yang akan berdampak pada kehidupannya di kemudian hari.

Masalah agama dan moral yang terjadi anak pekerja migran yakni belum tertib dalam menjalankan ibadah sesuai dengan keyakinannya. Pemahaman anak akan nilai-nilai agama dan moral berdampak pada pola perilaku dan tindakan dalam kesehariannya. Penyebab anak yang melakukan tindakan negatif dalam keterkaitan interaksi dengan orang lain adalah kurangnya pendidikan dari orangtua atau orang dewasa lain di sekitarnya serta anak juga sering melakukan peniruan atau imitasi yang tidak tepat sehingga memunculkan perilaku yang kurang sesuai dengan norma dan aturan setempat (Chusna et al., 2017; Setiawati, 2006). Dari hasil penelitian, belum tertibnya anak pekerja migran dalam menjalankan ibadah dikarenakan dua hal, yakni hilangnya sosok orangtua yang berperan menjadi model dalam beribadah dan pengasuh (grandparenting) yang tidak tegas dalam mendidik dalam hal agama dan moral meskipun telah mengajak dan memberikan contoh dalam beribadah shalat, sehingga anak lalai dalam menjalankan ibadahnya.

Masalah pribadi dan hubungan sosial juga dialami oleh anak pekerja migran. Anak pekerja migran lebih sulit diatur oleh pengasuh dan mengalami gejala-gejala disorientasi, marah, cemas, dan kurang bahagia sehingga berdampak pada perkembangan mental dan prestasi akademiknya (Raharto et al., 2013). Disamping itu, riset pada remaja di Filipina menunjukkan anak pekerja migran lebih berpotensi menunjukkan perilaku yang sama dilakukan oleh sebayanya seperti merokok, minum-minuman keras, dan penyalahgunaan narkoba (de Dios et al., 2013). Permasalahan pribadi dan hubungan sosial yang terjadi diakibatkan oleh lalainya orangtua pekerja migran dan pengasuh (grandparenting) dalam mendidik anak. Dengan kurang diberikannya keterampilan dalam hubungan sosial dan lebih membiarkan apapun yang dilakukan anak, maka anak tidak memiliki sikap tanggung jawab dan akan kesulitan menjalin hubungan sosial dengan orang lain.

Masalah anak pekerja migran dalam memanfaatkan hobi dan waktu luang yakni tidak mampu mengelola waktu luang dengan baik. Selaras dengan hal tersebut, sebuah penelitian menyebutkan anak memanfaatkan waktu luangnya untuk untuk menonton televisi, film dan video, bermain games online, membaca dan aktivitas fisik (Adhia, 2017). Penelitian lain menyebutkan bahwa anak memiliki kohesifitas yang tinggi dengan kelompok sebayanya, namun digunakan untuk kegiatan yang negatif (seperti menghabiskan waktu luang di warung kopi), lebih jauh anak berpikir bahwa rumah menjadi lingkungan yang menakutkan, tidak aman maupun nyaman (Kholis, 2017). Jika dikaitkan dengan keadaan anak pekerja migran, kohesifitas dengan kelompok sebaya dapat memiliki imbas yang negatif dan positif. Kesibukan orangtua pekerja migran dan pengasuh (grandparenting) bukanlah alasan untuk tidak mendidik anak dalam memanfaatkan hobi dan waktu luangnya. Pengawasan dan pemberian pemahaman yang rendah dari orangtua buruh terkait pemanfaatan waktu luang dapat mengakibatkan anak memilih melakukan aktivitas yang menurutnya menyenangkan tanpa mempertimbangkan baikburuknya aktivitas tersebut. Oleh karenanya, anak pekerja migran perlu dukungan dan pengawasan dalam pemanfaatan hobi dan waktu agar dapat dimanfaatkan secara positif.

Masalah masa depan yang berhubungan dengan jabatan yang terjadi yakni anak pekerja migran merasa kebingungan dalam mengambil langkah yang berhubungan dengan jabatan (karier). Penyebabnya tidak lain karena minimnya orientasi akan masa depan dan pendampingan dari pengasuh, sehingga anak 
tidak mendapatkan informasi yang benar. Sebuah hasil penelitian menyebutkan bahwa ada perbedaan persepsi pada anak pekerja migran laki-laki dan perempuan dalam memandang masa depan, anak lakilaki melihat sekolah tidak menjamin masa depan sedangkan anak perempuan melihatnya sebagai hal yang penting dan menjamin masa depan (Kholis, 2017). Selaras dengan hal tersebut, penelitian lain menyebutkan anak pekerja migran memiliki keinginan keluar negeri seperti orangtuanya (Purwatiningsih, 2016). Kondisi demikian disebabkan faktor lingkungan yang mayoritas warganya merupakan pekerja migran seperti orangtua mereka, meningkatnya perekonomian ketika pekerja migran, serta pengaruh dari teman sebayanya yang berorientasi menjadi pekerja migran.

Masalah kebiasaan pendidikan yang terjadi pada anak pekerja migran adalah: jam belajar yang tidak teratur, jam belajar hanya di malam hari, sukar mengingat materi yang dihafal, malas belajar, tidak dapat menerapkan cara belajar yang baik, mudah mengantuk, serta merasa belajar adalah kegiatan yang sulit dilakukan. Kejadian demikian tidak terlepas dari hilangnya peran orangtua. Orangtua semestinya merawat fisik dan mental anak agar sehat sesuai dengan proses tumbuh-kembangnya, serta memberikan kesejahteraan psikologis dan emosional agar anak dapat sukses dalam pendidikan (Yuniastuti, 2014). Temuan Kholis, (2017) menjelaskan bahwa persepsi anak terhadap sekolah berbeda. Ketika seorang anak ditinggal oleh ayahnya, persepsi sekolahnya lebih baik dibanding ketika anak ditinggal oleh ibunya. Tentunya, pendampingan dalam hal pendidikan dari orangtua dan pengasuh (grandparenting) yang baik, dengan penuh kesabaran, mendengarkan secara aktif, dan memberi dukungan terhadap pendidikan anak pekerja migran akan meningkatkan kebiasaan positif dalam hal pendidikan, sehingga anak akan lebih berprestasi.

Pada masalah muda-mudi dan asmara, anak pekerja migran mulai merasa tertarik terhadap lawan jenis. Orangtua yang menjadi pekerja migran tidak bisa memberikan pengawasan secara langsung kepada anak pekerja migran dan lemahnya pengasuh dalam pengawasan akan berdampak pada perilaku yang maladaptif ataupun justru menjadi korban pelecehan seksual. Apabila anak pekerja migran mendapatkan informasi pendidikan seks yang salah seperti dari gawai dan teman sebaya, maka anak akan mendapatkan pengetahuan seks yang tidak sesuai dengan tugas perkembangannya dan berdampak terhadap perilaku seks anak (Rahmawati, 2014). Guna mencegah agar anak tidak mengalami penyimpangan seksual dan memiliki pengetahuan fungsi reproduksi dengan menanamkan nilai moral dan etika, serta agar tidak menjadi korban pelecehan seksual diperlukan pendidikan seks sejak dini (Ratnasari \& Alias, 2016; Windijarti, 2011). Hilangnya peran orangtua dikarenakan menjadi pekerja migran akan berdampak pada pendidikan seks anak. Terkait dengan hal tersebut, pengasuh hendaknya memberikan pendidikan seks yang benar, mengingat anak pekerja migran mulai ada ketertarikan dengan lawan jenis. Dengan pendidikan seks, anak pekerja migran akan mendapatkan pengetahuan tentang seks dan mencegah anak mencoba hal-hal yang seharusnya belum diperbolehkan karena kurangnya informasi.

\section{Urgensi Bimbingan dan Konseling pada Poblematika Anak Pekerja migran}

Kewajiban pengasuhan anak pekerja migran yang utama ada pada orangtua. Meski demikian, anak pekerja migran pada waktu yang bersamaan menjadi peserta didik. Dalam lingkup institusi pendidikan tersebut, bimbingan dan konseling memiliki peranan yang penting (Barida \& Prasetiawan, 2018; BoluSteve \& Oredugba, 2017; Chusna et al., 2017; Lase, 2018; Onyango et al., 2018; Petra \& Jasna, 2017; Rosita et al., 2020; Salgong et al., 2016; Siregar, 2015). Peran konselor dalam penanganan masalah sosial anak sangat diperlukan terutama dari segi psikologisnya (Kumala et al., 2017).

Jenis layanan bimbingan dan konseling komprehensif, seperti layanan dasar, layanan responsif, perencanaan individual dan dukungan sistem mampu membantu dalam meningkatkan pertumbuhan dan perkembangan anak pekerja migran. Layanan dasar membantu semua peserta didik agar memperoleh perkembangan yang optimal (Fatimah, 2017; Hidayati, 2015; Huda et al., 2016; Khalilah, 2017; Luthfiah et al., 2018; Minsih, 2015; Sanderi et al., 2013). Melihat problematik yang ditemui pada anak pekerja migran di Tulungagung, layanan yang dapat diberikan antara lain: memberikan pemahaman pada masalah kesehatan (anak yang mengalami permasalahan berat badan/ obesitas), pemahaman akan kondisi keluarga yang berpisah karena bekerja maupun bercerai, memberikan bimbingan klasikal tentang penguatan dalam beribadah, memberikan informasi mengenai pengelolaan manajemen waktu, memberikan pengenalan tentang karier dan memberikan informasi tentang pola hubungan interpersonal 
yang positif. Dengan demikian, layanan dasar memiliki peranan dalam memberikan pengenalan, pemahaman pada situasi baru yang ada pada anak pekerja migran, memberikan pencegahan agar anak pekerja migran tidak menunjukkan perilaku yang maladaptif.

Salah satu faktor yang menyebabkan munculnya permasalahan anak pekerja migran adalah pola pengasuhan orangtua. Sebagai usaha membantu anak pekerja migran menyelesaikan masalah terkait pola asuh, layanan bimbingan dan konseling responsif dapat diimplementasikan. Temuan penelitian menyebutkan layanan responsif memiliki dampak positif terhadap pengembangan kompetensi anak, kesuksesan studi anak, dan serta dapat membantu orangtua menangani perilaku anak yang maladaptif (Nugraha \& Rahman, 2017; Supriyanto, 2016; Widodo, 2009). Untuk itu perlu adanya kunjungan rumah maupun kolaborasi antara konselor sekolah dengan orangtua atau pengasuh dalam menangani problematik anak pekerja migran. Temuan penelitian menyebutkan, layanan kolaborasi dan konsultasi serta kunjungan rumah telah dilaksanakan untuk memberikan pendampingan psikologi bagi pengasuh (grandparenting) dan anak. Dari kunjungan rumah, konselor dapat memahami anak pekerja migran secara komprehensif. Seperti halnya dalam masalah keluarga, pengasuhan anak pekerja migran yang sedang ditinggal orangtua dan bercerai, dapat mengakibatkan anak menjadi malas bersekolah. Dengan adanya layanan responsif, permasalahan-permasalahan yang dialami anak pekerja migran akan berkurang dan tidak mengganggu pertumbuhan dan perkembangannya.

Anak pekerja migran memiliki keinginan untuk menjadi pekerja migran sebagaimana orangtuanya, mereka juga mengalami kebingungan melanjutkan sekolah. Terkait dengan keadaan tersebut, bimbingan dan konseling dapat membantu anak pekerja migran untuk membuat perencanaan individual. Perencanaan individual meyakinkan anak dalam memilih sekolah lanjutan, memiliki aspirasi karier, mengeksplorasi peluang-peluang karier, mengeksplorasi latihan-latihan pekerjaan, memahami kebutuhan untuk kebiasaan bekerja yang positif, dan lebih jauh pada persiapan dalam dunia kerja (Hidayati, 2015; Kurniawan et al., 2019; Kusri, 2016; Pangestuti, 2017; Ramadhani, 2017). Dengan pemberian layanan perencanaan individual, anak pekerja migran akan belajar untuk merancang, merencanakan dan mengelola segala bentuk aktivitas yang berkaitan dengan perencanaan masa depan. Sehingga harapannya anak pekerja migran mendapatkan wawasan baru dan merubah perspektif tentang masa depan karier bagi dirinya. Layanan bimbingan dan konseling diberikan kepada anak pekerja migran dan pada orangtua maupun pengasuh sesuai dengan kondisi yang dialami anak pekerja migran, sehingga anak akan mampu tumbuh dan berkembang secara optimal dan tidak terganggu akan permasalahan yang dialaminya.

\section{SIMPULAN}

Masalah yang muncul pada anak pekerja migran di antaranya adalah: masalah kesehatan, masalah keadaan kehidupan ekonomi, masalah keluarga, masalah agama dan moral, masalah pribadi, masalah hubungan sosial dan organisasi, masalah hobi dan penggunaan waktu luang, masalah yang berhubungan dengan jabatan, masalah kebiasaan pendidikan, masalah muda-mudi dan asmara. Faktor dominan yang memengaruhi anak pekerja migran adalah pengasuhan. Anak pekerja migran memiliki masalah yang unik dan kompleks, oleh karenanya bimbingan dan konseling memiliki peranan penting dalam membantu anak pekerja migran, orangtua ataupun pengasuhnya. Bantuan tersebut dapat diberikan lewat layanan dasar, layanan responsif dan perencanaan individual. Bagi dunia pendidikan, studi ini akan memberikan pemahaman tentang konteks masalah anak pekerja migran dan akan memberikan kemungkinan pemecahan masalah anak pekerja migran melalui pelibatan berbagai stakeholders. Bagi bimbingan dan konseling, studi ini dapat dimanfaatkan untuk pengembangan layanan bimbingan dan konseling komprehensif yang secara khusus menangani permasalahan anak pekerja migran, baik yang berfungsi pemahaman, pencegahan, pengembangan, penyaluran, dan kuratif.

\section{DAFTAR RUJUKAN}

Adhia, A. (2017). Perilaku pemanfaatan waktu luang di kalangan siswa SMP dan SMA di Surabaya. Universitas Airlangga.

Arfyansyah, H. (2016). Pemenuhan hak anak oleh keluarga TKI: Studi di Desa Keboireng, Kecamatan Besuki, Kabupaten Tulungagung. Universitas Islam Negeri Maulana Malik Ibrahim. 
Barida, M., \& Prasetiawan, H. (2018). Urgensi pengembangan model konseling kelompok teknik self management untuk meningkatkan kecerdasan moral siswa SMP. Jurnal Fokus Konseling, 4(1), 27. https://doi.org/10.26638/ jfk.439.2099

Basmalah, B., Endang, B., \& Lestari, S. (2016). Pengaruh layanan orientasi terhadap penyesuaian diri dalam kegiatan belajar di sekolah. Jurnal Pendidikan dan Pembelajaran Khatulistiwa, 5(10), 1-12.

Berns, R. M. (2004). Child, family, school, community socialization and support (9th ed.). Thamson learning.

Bogdan, R. C., \& Biklen, S. K. (2007). Qualitative research for education, An introduction to theory and methods. (5th ed.). Allyn and Bacon, Inc.

Bolu-Steve, F., \& Oredugba, O. O. (2017). Influence of counselling services on perceived academic performance of secondary school students in Lagos State. International Journal of Instruction, 10(2), 211-228.

Brooks, J. (2012). The process of parenting.

Chusna, A., Triyono, \& M. Ramli. (2017). Profil moralitas anak buruh migran indonesia. Jurnal Pendidikan: Teori, Penelitian, dan Pengembangan, 2(3), 371-376.

de Dios, A., Dungo, N., \& Reyes, M. (2013). Patterns, trends and challenges of labour migration in the Philippines: focus on families and children left behind. In N. Dungo, A. Jampaklay, de D. Aurora, A. Raharto, \& M. Reyes (Eds.), Valuing the social cost of migration: An exploratory study (pp. 72-116). UNESCO.

Eriyanti, I. O., Susilo, H., \& Riyanto, Y. (2019). Analisis pola asuh grandparenting dalam pembentukan karakter anak di TK Dharma Wanita di Desa Drokilo Kecamatan Kedungadem Kabupaten Bojonegoro. Jurnal Pendidikan untuk Semua, 3(1), 9-16.

Fatimah, D. N. (2017). Layanan bimbingan klasikal dalam meningkatkan self control siswa SMP Negeri 5 Yogyakarta. Hisbah: Jurnal Bimbingan Konseling dan Dakwah Islam, 14(1), 25-37. https://doi.org/10.14421/ hisbah.2017.141-03

Fauziah, H., Hastuti, D., \& Yuliati, L. N. (2020). Parenting practice, parental involvement in school, child's self concept and school readiness. Jurnal Ilmu Keluarga dan Konsumen, 13(1), 61-74. https://doi.org/10.24156/ jikk.2020.13.1.61

Fauziah, R. R., Kusumawardani, R., \& Maryani, K. (2018). Perbedaan kemandirian anak ditinjau dari subyek pengasuhan orangtua dan kakek-nenek pada anak usia 5-6 tahun. Jurnal Penelitian dan Pengembangan Pendidikan Anak Usia Dini (JPPPAUD FKIP Untirta), 5(1), 71-80.

Feist, J., Feist, G. J., \& Roberts., O.-A. (2018). Teori kepribadian (8th ed.). Salemba Humanika.

Hidayati, R. (2015). Layanan informasi karier membantu peserta didik dalam meningkatkan pemahaman karier. Jurnal Konseling Gusjigang, 1(1).

Hu, F. (2013). Does migration benefit the schooling of children left behind? Demographic Research, $29,33-70$. https://doi.org/10.4054/DemRes.2013.29.2

Huda, A., Endang, B., \& Astuti, I. (2016). Layanan orientasi sekolah oleh guru bimbingan dan konseling pada siswa kelas VII SMP Negeri 5 Pontianak. Jurnal Pendidikan dan Pembelajaran Khatulistiwa, 5(11), 1-10.

Ip, P., Rao, N., Bacon-Shone, J., Li, S. L., Ho, F. K., Chow, C., \& Jiang, F. (2016). Socioeconomic gradients in school readiness of Chinese preschool children: The mediating role of family processes and kindergarten quality. Early Childhood Research Quarterly, 35(2), 111-123. https://doi.org/10.1016/j.ecresq.2015.10.005

Johnston, L. G., McLaughlin, K. R., El Rhilani, H., Latifi, A., Toufik, A., Bennani, A., Alami, K., Elomari, B., \& Handcock, M. S. (2015). Estimating the size of hidden populations using respondent-driven sampling data. Epidemiology, 26(6), 846-852. https://doi.org/10.1097/EDE.0000000000000362

Khalilah, E. (2017). Layanan bimbingan dan konseling pribadi sosial dalam meningkatkan keterampilan hubungan sosial siswa. JIGC (Journal of Islamic Guidance and Counseling), 1(1), 41-57.

Kholis, N. (2017). Pola asuh dan persepsi sekolah anak buruh migran. YINYANG: Jurnal Studi Islam, Gender dan Anak, 12(1), 35-56. https://doi.org/10.24090/yinyang.v12i1.2017.pp35-56

Kumala, M., Nurlaili, I. R., \& Dewi, N. K. (2017). Urgensi peran konselor dalam mengatasi masalah-masalah sosial anak. Prosiding SNBK (Seminar Nasional Bimbingan dan Konseling), 1(1), 159-169.

Kurniasari, N. D., Rachmad, T. H., Herowati, D., \& Srihastuti, I. (2019). Pola pengasuhan remaja pada keluarga buruh migran indonesia ( BMI ) untuk mewujudkan generasi berkualitas di Kecamatan PengantenanPamekasan. Komunikasi, 12(2), 141-162. https://doi.org/10.21107/ilkom.v12i2

Kurniawan, S. J., Kumara, A. R., \& Bhakti, C. P. (2019). Strategi layanan perencanaan individual untuk mengembangkan work readiness pada siswa SMK. Seminar Nasional Pendidikan (Sendika), 3, 109-116.

Kusri, A. M. (2016). Pengaruh layanan informasi peminatan terhadap kemantapan pilihan sekolah lanjutan. Jurnal Psikologi Pendidikan \& Konseling, 2(1), 49-57. 
Langinan, S., Tulusan, F., \& Plangiten, N. (2014). Pengaruh kondisi sosial ekonomi keluarga terhadap partisipasi masyarakat dalam pembangunan pendidikan (Suatu studi di Kecamatan Pulutan Kabupaten Kepulauan Talaud). Jurnal Administrasi Publik, 4(5).

Lase, B. P. (2018). Posisi dan urgensi bimbingan konseling dalam praktik pendidikan. Jurnal Warta, 58(1), 1-17.

Luthfiah, Q., Yuline, Y., \& Wicaksono, L. (2018). Studi tentang layanan orientasi pada peserta didik kelas VII di MTs Al-Irsyad Pontianak. Jurnal Pendidikan dan Pembelajaran, 7(8), 1-8.

Magdalena, S. M. (2013). Social and emotional competence-predictors of school adjustment. Social and Behavioral Sciences, 76(3), 20-33.

Marti, M., Merz, E. C., Repka, K. R., Landers, C., Noble, K. G., \& Duch, H. (2018). Parent involvement in the getting ready for school intervention is associated with changes in school readiness skills. Frontiers in Psychology, 9, 1-15. https://doi.org/10.3389/fpsyg.2018.00759

Minsih. (2015). Pelaksanaan layanan dasar bimbingan dalam membentuk karakter siswa di SD Muhammadiyah program khusus Kota Surakarta. Jurnal Profesi Pendidikan Dasar, 2(2), 112-120.

Moleong, L. (2005). Metodologi penelitian kualitatif. PT. Remaja Rosdakarya.

Muslihati, M. (2019). Peran bimbingan dan konseling dalam penguatan pendidikan karakter di sekolah menengah kejuruan. Jurnal Kajian Bimbingan dan Konseling, 4(3), 101-108. https://doi.org/10.17977/ um001v4i32019p101

Nugraha, A., \& Rahman, F. A. (2017). Strategi kolaborasi orangtua dengan konselor dalam mengembangkan sukses studi siswa. Jurnal Konseling GUSJIGANG, 3(1), 128-136.

Nurannisa, H., Hasanah, U., \& Tarma, T. (2017). Pengaruh granparenting terhadap perkembangan emosi remaja pada keluarga TKI di Kecamatan Gekbrong Cianjur-Jawa Barat. JKKP (Jurnal Kesejahteraan Keluarga dan Pendidikan), 4(2), 62-65. https://doi.org/10.21009/JKKP.042.02

Onyango, P. A., Aloka, P. J., \& Raburu, P. (2018). Effectiveness of guidance and counseling in the management of student behaviour in public secondary schools in Kenya. International Journal of Applied Psychology, 8(1), $6-11$.

Pangestuti, R. W. (2017). Strategi layanan perencanaan individual. Prosiding Seminar Nasional Peran Bimbingan dan Konseling dalam Penguatan Pendidikan Karakter, 159-172.

Petra, G. M., \& Jasna, M. (2017). The role of the school counsellor in school-community collaboration: The case of Slovenia. International Journal of Cognitive Research in Science, Engineering and Education, 5(1), 1-29.

Pramono, J. (2018). Ratusan anak buruh migran bermasalah di sekolah. https://www.tulungagungtimes.com/.

Purwatiningsih, S. (2016). Respons anak-anak migran terhadap migrasi internasional di Perdesaan Ponorogo. Populasi, 24(1), 57-71. https://doi.org/10.22146/jp.23695

Puspitawati, H., \& Setioningsih, S. S. (2011). Fungsi pengasuhan dan interaksi dalam keluarga terhadap kualitas perkawinan dan kondisi anak pada keluarga tenaga kerja wanita (TKW). Jurnal Ilmu Keluarga dan Konsumen, 4(1), 11-20. https://doi.org/10.24156/jikk.2011.4.1.11

Putri, S. J. (2014). Hubungan antara tingkat kebugaran jasmani (physical fitness) dan kesehatan mental (mental hygiene) dengan prestasi belajar pendidikan jasmani (penjas) siswa SD. Universitas Pendidikan Indonesia.

Raharto, A., Noveria, M., Romdiati, H., Fitranita, Malamassam, M. A., \& Hidayati, I. (2013). Indonesian labour migration: social costs and families left behind. UN Women: Valuing The Social Costs of Migration. 18-71.

Rahmawati, E., \& Diana. (2016). Difference of children ages 5-6 years of independence viewed from the caregiver (parents and grandparents) in Kindergarten Kartini 1 and Kartini 2. Belia, 5(1), 13-17.

Rahmawati, M. (2014). The sexuality knowledge construction of primary school students. Universitas Jember.

Ramadhani, E. (2017). Efektivitas layanan informasi dalam meningkatkan aspirasi karier siswa. Wahana Didaktika, $15(2), 57-66$.

Ratnasari, R. F., \& Alias, M. (2016). Pentingnya pendidikan seks untuk anak usia dini. Jurnal Tarbawi Khatulistiwa, $2(2), 55-59$.

Riasih, T. (2018). Pola dan strategi pengasuhan anak oleh pekerja migran di Kota Bandung. Pekerjaan Sosial, 17(1), 104-121. https://doi.org/10.31595/peksos.v17i1.132

Romdiati, H. (2016). Migrasi tenaga kerja indonesia dari Kabupaten Tulungagung: Kecenderungan dan arah migrasi, serta remitansi. Jurnal Kependudukan Indonesia, 7(2), 27-53.

Rosita, T., Irmayanti, R., \& Hendriana, H. (2020). Urgensi bimbingan karier di sekolah dasar. Abdimas Siliwangi, 3(1), 199-205. 
Sa'adah, R. H., Herman, R. B., \& Sastri, S. (2014). Hubungan status gizi dengan prestasi belajar siswa Sekolah Dasar Negeri 01 Guguk Malintang Kota Padangpanjang. Jurnal Kesehatan Andalas, 3(3). https://doi. org/10.25077/JKA.V3I3.176

Salgong, V. K., Ngumi, O., \& Chege, K. (2016). The role of guidance and counseling in enhancing student discipline in secondary schools in Koibatek District. Journal of Education and Practice, 7(13), 142-151.

Sanderi, F., Marjohan, M., \& Sukmawati, I. (2013). Kepatuhan siswa terhadap disiplin dan upaya guru BK dalam meningkatkannya melalui layanan informasi. Konselor, 2(1), 220-224. https://doi.org/10.24036/02013211008$0-00$

Setiawati, E., Livana. P. H., \& Susanti, Y. (2017). Hubungan konsep diri dengan kualitas hidup anak usia sekolah pada keluarga buruh migran internasional. Indonesian Journal for Health Sciences, 1(2), 21-28. https://doi. org/10.24269/ijhs.v1i2.2017.6

Setiawati, F. A. (2006). Pendidikan moral dan nilai-nilai agama pada anak usia dini: Bukan sekedar rutinitas. Paradigma: Jurnal Psikologi Pendidikan dan Konseling, 1(2), 41-48.

Siregar, R. (2015). Urgensi konseling keluarga dalam menciptakan keluarga sakinah. HIKMAH: Jurnal Ilmu Dakwah dan Komunikasi Islam, 2(1), 77-91.

Supriyanto, A. (2016). Kolaborasi konselor, guru, dan orang tua untuk mengembangkan kompetensi anak usia dini melalui bimbingan komprehensif. Jurnal CARE (Children Advisory Research and Education), 4(1), 1-8.

Suryadi. (2017). Perlindungan anak buruh migran di Kabupaten Cirebon (Analisis terhadap konsep dampak anak yang ditinggalkan). Jurnal Empower Pengembangan Masyarakat Islam, 2(1), 1-16.

Wahyuningsih, E., \& Wulan, T. R. (2019). Profil pengasuh dan masalah anak yang ditinggalkan pada keluarga buruh migran indonesia. Jurnal Kesmas Indonesia, 11(1), 76-89.

Wahyuningsih, E., \& Wulan, T. R. (2016). The profile of caregiver and problems of children left behind (CLB) among indonesian migrant worker families. International Workshop on Maximising Migration Benefits (M2B): Indonesian Migrant Workers' Health and Wellbeing from Security to Development, 19-21.

Wahyuningsih, S., \& Jatiningsih, O. (2017). Pola asuh anak keluarga tenaga kerja wanita (TKW) di Desa Arjowilangun Kecamatan Kalipare Kabupaten Malang. Kajian Moral dan Kewarganegaraan, 5(3).

Widiasari, Y., Pujiati, D., \& Purwokerto. (2017). Pengasuhan anak usia dini bagi orang tua pekerja. Jurnal Ilmiah Pendidikan PraSekolah dan Sekolah Awal, 2(2), 68-77.

Widodo, B. (2009). Layanan konsultasi orang tua salah satu bidang layanan bimbingan konseling untuk membantu mengatasi masalah anak (Sebuah refleksi analitis). Jurnal Ilmiah Widya Warta, 33(1), 1-20.

Windijarti, I. (2011). Komunikasi interpersonal orang tua dan anak dalam pendidikan seksual. Jurnal Ilmu Komunikasi, 9(3), 274-292.

Yuniastuti. (2014). Kehidupan sosial ekonomi TKI dan TKW serta dampak sosial psikologis pendidikan anak. Jurnal Ilmiah Pendidikan Pancasila dan Kewarganegaraan, 27(1), 69. https://doi.org/10.17977/jppkn. v27i1.5525 